\title{
Large-scale synthesis of YSZ nanopowder by Pechini method
}

\author{
MORTEZA HAJIZADEH-OGHAZ ${ }^{\mathrm{a}, *}$, REZA SHOJA RAZAVI ${ }^{\mathrm{a}}$ and \\ MOHAMMADREZA LOGHMAN ESTARKI ${ }^{\mathrm{b}}$ \\ ${ }^{a}$ Maleke Ashtar University of Technology, Shahinshahr 831415/115, Iran \\ ${ }^{\mathrm{b}}$ Isfahan University of Technology, Isfahan, Iran
}

MS received 22 April 2013; revised 4 July 2013

\begin{abstract}
Yttria-stabilized zirconia nanopowders were synthesized on a relatively large scale using Pechini method. In the present paper, nearly spherical yttria-stabilized zirconia nanopowders with tetragonal structure were synthesized by Pechini process from zirconium oxynitrate hexahydrate, yttrium nitrate, citric acid and ethylene glycol. The phase and structural analyses were accomplished by $\mathrm{X}$-ray diffraction; morphological analysis was carried out by field emission scanning electron microscopy and transmission electron microscopy. The results revealed nearly spherical yttria-stabilized zirconia powder with tetragonal crystal structure and chemical purity of $\mathbf{9 9 . 1 \%}$ by inductively coupled plasma optical emission spectroscopy on a large scale.
\end{abstract}

Keywords. Sol-gel; yttria-stabilized zirconia; large scale; nanopowder; Pechini method.

\section{Introduction}

Zirconia has attracted the attention of many scientists because of its tremendous thermal, mechanical and electrical properties (Kingery et al 1959; Subbarao 1981; Badwal and Ciacchi 2000; Casellas Feder et al 2001). Among its possible applications, the one that has gained the greatest attention is its use in thermal barrier coatings (TBCs). At atmospheric pressure, pure zirconia has three solid polymorphs which show monoclinic, tetragonal and cubic symmetries. The use of pure zirconia ceramics as an advanced structural material is limited due to the impulsive tetragonal to monoclinic $(t \rightarrow m)$ phase transformation by cooling from elaborative temperature to room temperature. The transformations between different polymorphs are important for the mechanical properties of zirconia ceramics. It has been well documented in the literature (Rühle and Evans 1989; Kisi and Howard 1998; Roebben et al 2003; Hannink et al 2004) that the $t \rightarrow m$ transformation in pure undoped zirconia during cooling is a reversible athermal martensitic transformation, associated with a large temperature hysteresis (around $200{ }^{\circ} \mathrm{C}$ for undoped zirconia) and a finite quantity of volume change (4-5\%). This leads to catastrophic failures of the thermal barrier coating made from pure zirconia. Several dopants (yttria, ceria, calcia, magnesia, etc) are frequently added to stabilize the high temperature

*Author for correspondence

(morteza_hajizade1367@yahoo.com; Hajzadeh@mut-es.ac.ir) $\mathrm{t}$ and/or c-phase in coated microstructure. Yttriastabilized zirconia (YSZ) powders have tremendous potential in thermal barrier coatings as well as electronic and catalyst applications (Gongyi and Yuli 1992). The conventional methods of preparation are not appropriate because of inhomogeneity, diverse particle size distribution and poor reactivity (Simon 1991). Therefore, many different wet chemical methods, e.g. decomposition of citrates, hydrolysis of metal alkoxides, conventionalhydrothermal and sol-gel, have been studied in the continuing search for better and inexpensive zirconia powders (Mazdiyasni et al 1965, 1967; Marcilly et al 1970; Claussen 1984; Somiya 1991). Each technique has its own benefits as well as some restrictions, which are discussed in the literature (Claussen 1984). In the present study, YSZ powders were synthesized under Pechini circumstances using a hot plate stirrer and zirconyloxy chloride and yttrium nitrate as starting materials with citric acid and ethylene glycol as chelating and polymerization agents, respectively. The nominal composition chosen for the present study is $7 \mathrm{wt} \%$ YSZ, because it is reported in the literature that $6 \leq \mathrm{yttria} \leq 8 \mathrm{wt} \%$ is required to achieve metastable tetragonal phase of zirconia. In previous work, we have described the preparation of YSZ via a polymeric method. By controlling the synthesis parameters of the sol, agglomerated powders have been prepared (Oghaz et al 2012). The size of the primary particle is about $40-50 \mathrm{~nm}$. Then, the purpose of this work is to synthesize spherical particles of YSZ nanopowders using the same synthesis process on a largescale amount. 


\section{Experimental}

\subsection{Materials and physical measurements}

Morphology of the powder was investigated by field emission scanning electron microscopy (Hitachi Ltd., S4160) and transmission electron microscopy (Philips CM 200 FEG, The Netherlands). The crystalline structure of the powder was determined by X-ray diffraction analysis (Philips, CIII Rigaku D-Max). X-ray diffraction analysis was performed using $\mathrm{CuK} \alpha$ on heat-treated samples to distinguish cubic and tetragonal phases. A constant step scanning X-ray diffraction analysis was mannered in the $2 \theta$ range of $20-90$ at a scanning rate of $0.001 \mathrm{~s}^{-1}$, using a CIII Rigaku D-Max-based Philips diffractometer to examine the presence of any major peaks related with the monoclinic phase. Chemical composition of calcinated powder was determined by inductively coupled plasma optical emission spectroscopy (ICP-OES-Optima7300DV).

\subsection{Synthesis of 7 YSZ nanopowder}

A large amount of nanocrystalline $7 \mathrm{wt} \%$ YSZ was synthesized via Pechini's process by using of zirconium oxychloride $\left(\mathrm{ZrOCl}_{2} \cdot 6 \mathrm{H}_{2} \mathrm{O}\right)$ and yttrium nitrate $\left(\mathrm{Y}\left(\mathrm{NO}_{3}\right)_{3} \cdot 6 \mathrm{H}_{2} \mathrm{O}\right)$ as sources of metal salt precursors. By dissolving proper molar ratio of zirconium oxychloride and yttrium nitrate in two distinct beakers of distilled water and further mixing them, the solution was put in order. The amount of yttrium in the starting solution was selected so that the final weight ratio of $\mathrm{Y}_{2} \mathrm{O}_{3}$ to $\mathrm{ZrO}_{2}$ was 7:93 (7 wt\% YSZ). Citric acid (CA) was added after homogenization of the solution, to chelate with cations. The molar ratio of citric acid to total metal ions $(\mathrm{Zr}+\mathrm{Y})$ was 4:1. Following this dissolution, the solution was blended with ethylene glycol (EG) to endorse esterification reaction. The molar ratio of CA : EG was $1: 1$. Then the solution was heated on a hot plate at three different temperatures of 100,200 and $300{ }^{\circ} \mathrm{C}$ for 2,2 and $8 \mathrm{~h}$, respectively while being stirred by a magnetic stirrer to get a gelatinous solution. Finally, the viscous solution started setting as a gel-like mass. The obtained gel was heat treated at $1000{ }^{\circ} \mathrm{C}$ for $2 \mathrm{~h}$. The flowchart of the synthesis process is shown in figure 1.

\section{Results and discussion}

\subsection{Morphology of nanopowders}

According to the optimum levels of process we obtained in our previous work, namely by using zirconium oxychloride, solution $\mathrm{pH}=1$ and calcination at $1000{ }^{\circ} \mathrm{C}$ for $2 \mathrm{~h}$, large-scale amount of 7 YSZ nanopowder was synthesized successfully by means of Pechini process (Oghaz et al 2012). As well as for laboratory-scale synthesis, the aim of the experiments was to obtain nearly spherical shape of particles and finer particles. Field emission scanning electron microscopy (FESEM) and transmission electron microscopy (TEM) of powders were desirable in both shape and particle size (figures 2 and 3). Furthermore, particle size distribution by accumulative percent diagram for different calcination temperatures at 600, 800 and $1000{ }^{\circ} \mathrm{C}$ is illustrated in figure 4 .

\subsection{Structural investigation of nanopowders by X-ray diffraction}

X-ray diffraction patterns of the large-scale 7 YSZ nanopowder prepared from zirconium oxychloride, solution $\mathrm{pH}=1$ and calcinated at $1000^{\circ} \mathrm{C}$ for $2 \mathrm{~h}$ are shown in figure 5. Patterns correspond to YSZ and no peaks matching yttrium oxide or monoclinic YSZ are detected. From broadening of $\mathrm{X}$-ray peaks, size of the crystallites was determined with the Sherrer formula $D=K \lambda / \beta \cos \theta$, where $K$ is a constant equal to 0.9 due to the pseudoVoigt modification of the diffractograms; $\lambda$ the wavelength; $\beta$ the middle height width of the most intense peak and $\theta$ the value of the diffraction. The average crystallite size was $29 \mathrm{~nm}$.

\subsection{Effect of a large-scale synthesis}

In the final industrialization of the process, a study of the synthesis in large amounts has been carried out. The experimental route using citric acid, with the molar ratio $\mathrm{CA} / \mathrm{Zr}$ equal to 4 , has been designated referring to the different results earlier obtained (Laberty-Robert et al 2001; Oghaz et al 2012). Syntheses were done following the mechanism presented in the flowchart of figure 1, with molar ratio CA/EG equal to 1 (Laberty-Robert et al 2001). A scale factor of 10 and then 30 was applied for the quantity of precursors. With the standard synthesis, approximately $1 \mathrm{~g}$ of powder was achieved. To compare with, 10 and $30 \mathrm{~g}$ of powder were achieved by multiplying the precursor quantity by 10 and 30, respectively. The total duration for gel formation in large-scale synthesis of YSZ nanopowder is $12 \mathrm{~h}$ despite of lab-scale synthesis which is only $3 \mathrm{~h}$, and that is due to extensive use of starting materials, namely zirconium oxycholoride octahydrate, yttrium nitrate hexahydrate, citric acid, ethylene glycol and distilled water this is the main kinetic difference between large-scale synthesis and labscale synthesis of YSZ nanopowder. Furthermore, in lab scale, we obtained only $1 \mathrm{~g}$ YSZ nanopowder, while in large scale, we successfully obtained $30 \mathrm{~g}$ YSZ nanopowder by multiplying the optimum amounts of lab scale to 30. Consequently, large-scale synthesis has been followed like lab scale and the only change in the process parameter is increasing the total duration of gel formation. 


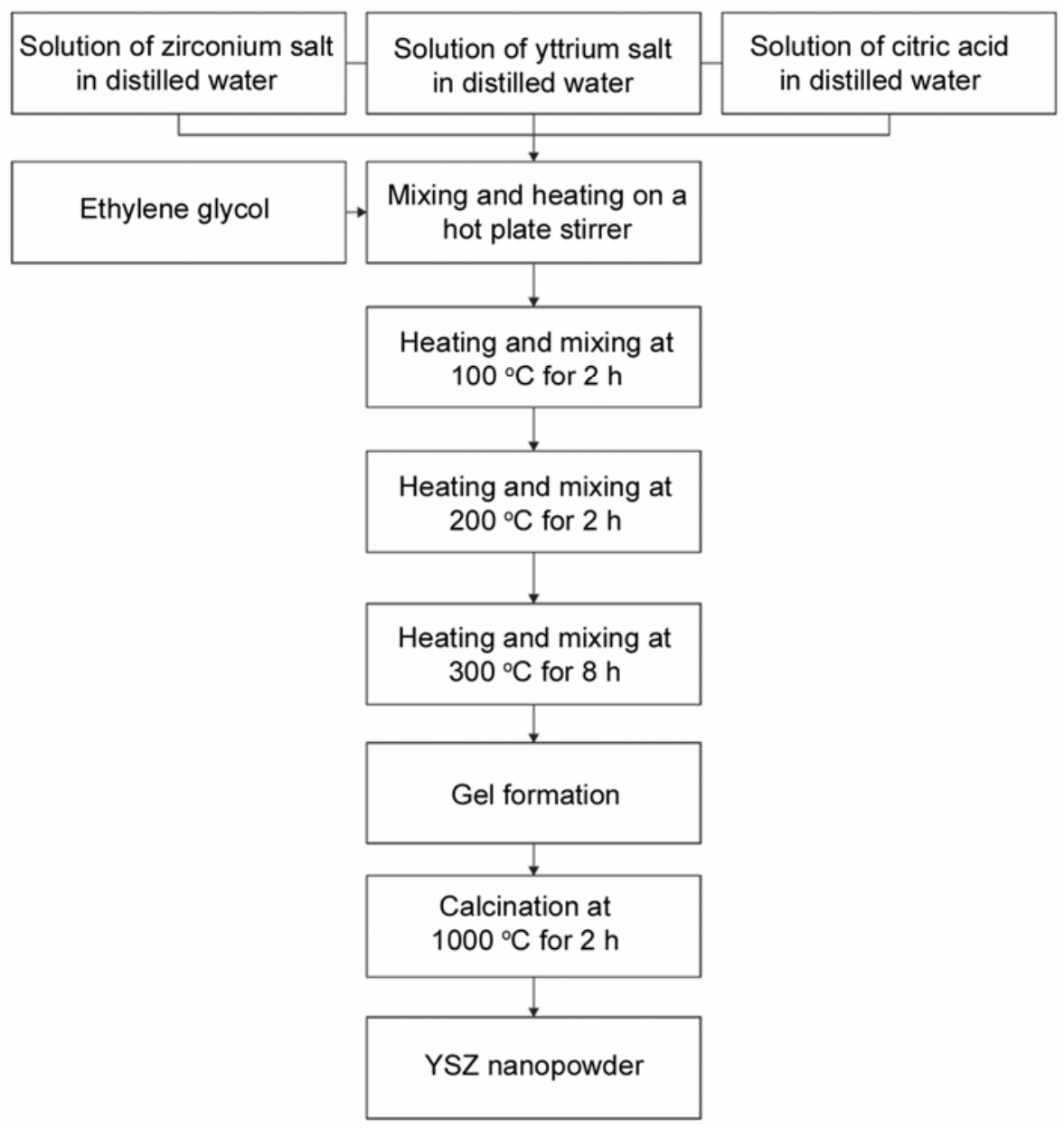

Figure 1. Flowchart for preparing YSZ powders by Pechini’s method.
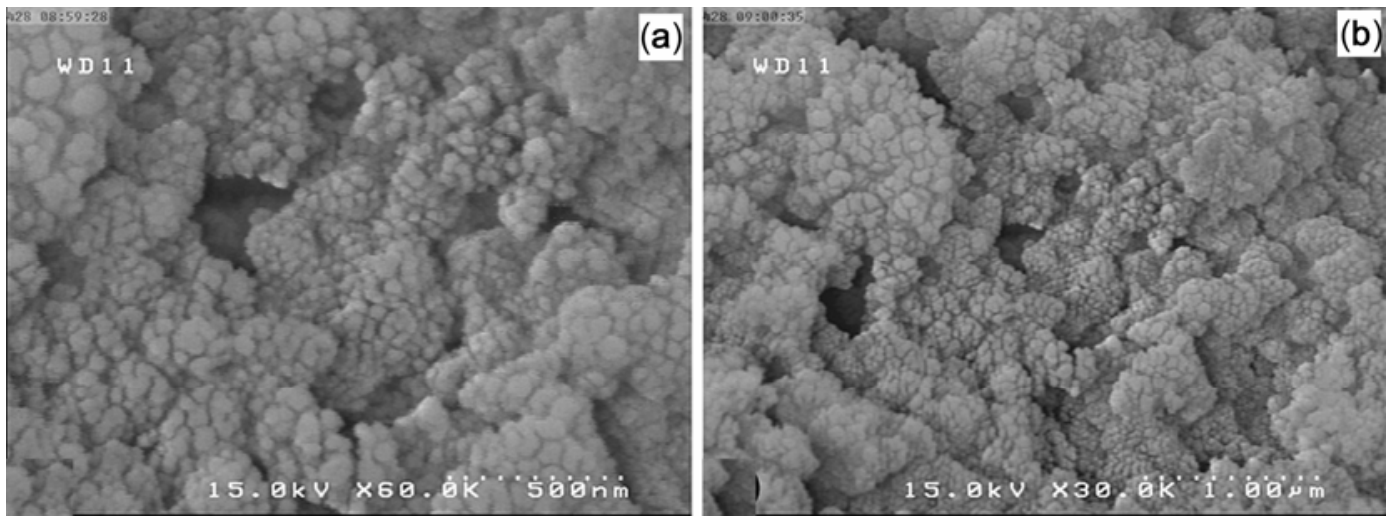

Figure 2. Scanning electron micrograph of large-scale synthesis of 7 YSZ powder at different magnifications: (a) $\times 60$ and (b) $\times 30$.

Furthermore, in other similar works by Farhikhteh et al (2010), the agglomerated size of YSZ powder was $90 \mathrm{~nm}$ with $\mathrm{EG}: \mathrm{Zr}^{4+}=\mathrm{CA}: \mathrm{Zr}^{4+}$, equal to $4: 1$ calcined at $650{ }^{\circ} \mathrm{C}$ for $2 \mathrm{~h}$. Moreover, Costa and Muccillo (2010) also obtained scandia-stabilized zirconia (ScSZ), which mainly consisted of hard agglomerates exhibiting irregular shapes with faceted borders, often lengthened, with an average size around $20 \mu \mathrm{m}$. However, these hard agglomerates consist of sintered nanoparticles resulting from the high-energy environment during thermal decomposition 
of the large amount of organic compounds used in the synthesis of the polymeric precursors. They used Pechini method with $1 \mathrm{Zr}^{4+}: 4 \mathrm{CA}: 16 \mathrm{EG}$ at $500-650{ }^{\circ} \mathrm{C} / 4 \mathrm{~h}$. However, in the present work, the average agglomerated size

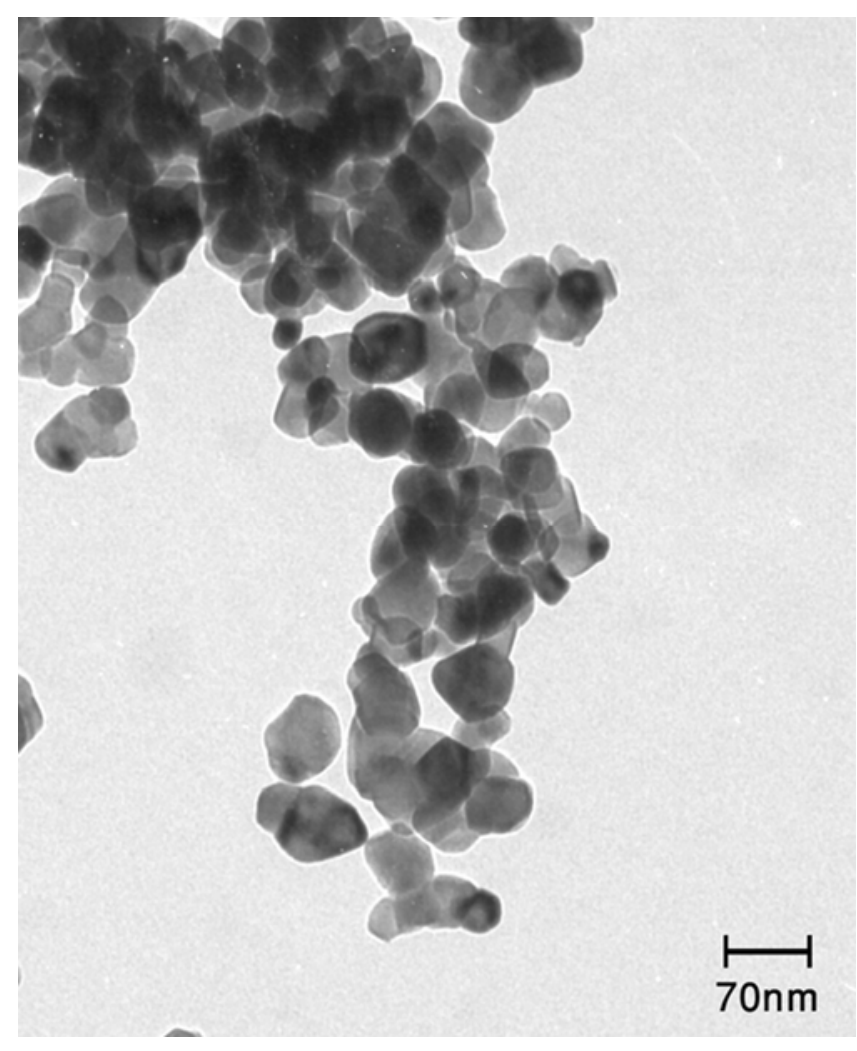

Figure 3. Transmission electron micrograph of large-scale 7 YSZ powder.

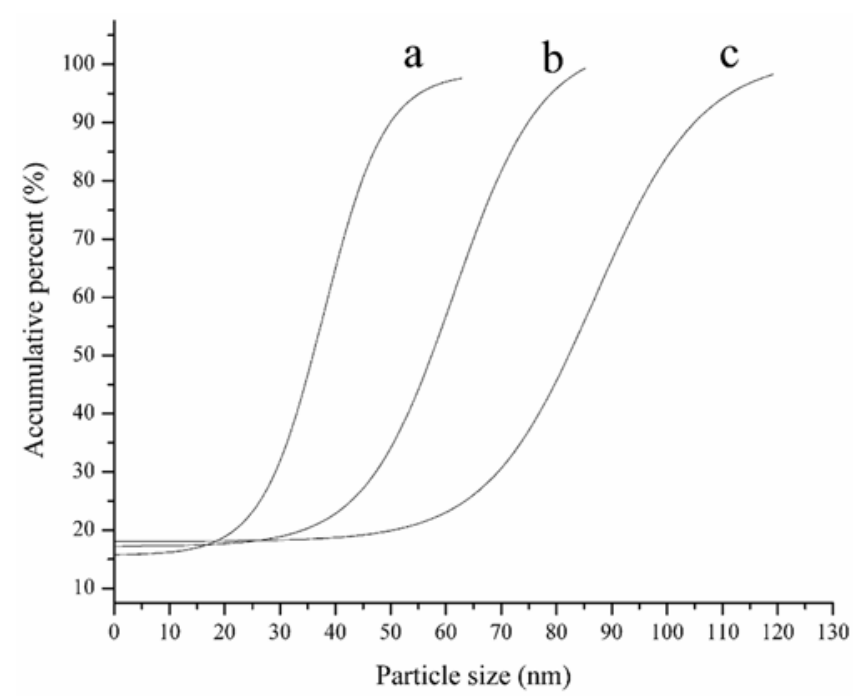

Figure 4. Particle size distribution by accumulative percent diagram at different calcination temperatures: (a) 600 $(\mathrm{D} 50=36 \mathrm{~nm}$, D90 = $50 \mathrm{~nm}), \quad(\mathbf{b}) 800(\mathrm{D} 50=57 \mathrm{~nm}, \mathrm{D} 90=$ $74 \mathrm{~nm})$ and $(\mathbf{c}) 1000{ }^{\circ} \mathrm{C}(\mathrm{D} 50=82 \mathrm{~nm}, \mathrm{D} 90=104 \mathrm{~nm})$. was $60 \mathrm{~nm}$ and consisted of primary particles with $\sim 20$ $30 \mathrm{~nm}$ diameters, as obtained by $\mathrm{EG}: \mathrm{Zr}^{4+}=4: 1$ at the higher calcination temperature $\left(1000^{\circ} \mathrm{C}\right)$ for $2 \mathrm{~h}$ (figure 3 ).

In the present work, applying higher calcination temperature released high volatile gases. The removal of volatile masses during calcinations at elevated temperatures plays a significant role in the variation of crystallite sizes. In the Pechini method, the polymeric distribution and its subsequent removal during thermal treatment is expected to control the particle growth and the final morphology of the particles. Furthermore, an increase in CA : $\mathrm{Zr}^{4+}$ mole ratio from $4: 1$ (present work) to $4 \cdot 77: 1$ (Laberty-Robert et al 2001) work resulted in slow decomposition of the salts and incomplete combustion of the CA-metal complexes. Thus, a lot of carbonaceous matter was left in the as-prepared powder. During calcinations, the removal of gaseous products from the precursor gave rise to capillary forces on particles, which brought more particles to come in contact with each other. This resulted in more particle agglomeration, cluster formation and particle growth during synthesis. Thus, there was an increase in particle size with the CA content in the Laberty-Robert et al (2001) work in comparison with the present work. Also, chemical purity of $99.1 \%$

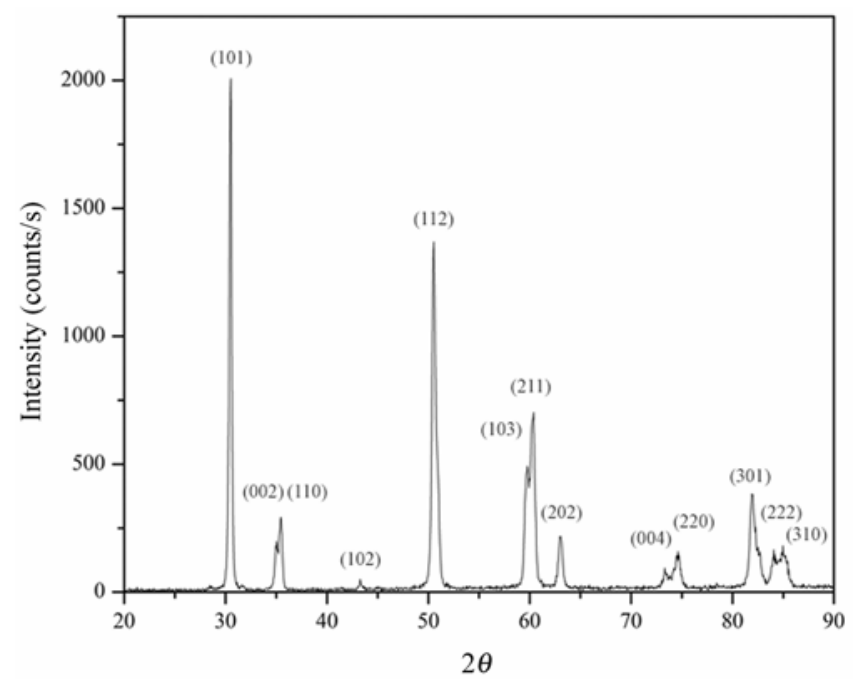

Figure 5. Powder X-ray diffraction patterns of 7 YSZ powder.

Table 1. Chemical composition determined by inductively coupled plasma optical emission spectroscopy (ICP) of YSZ powder calcined at $1000^{\circ} \mathrm{C}$.

\begin{tabular}{lc}
\hline Element & Content (\%) \\
\hline $\mathrm{ZrO}_{2}$ & $90 \cdot 21$ \\
$\mathrm{Y}_{2} \mathrm{O}_{3}$ & $6 \cdot 5$ \\
$\mathrm{HfO}_{2}$ & $2 \cdot 39$ \\
Others & $0 \cdot 9$ \\
\hline
\end{tabular}


by inductively coupled plasma optical emission spectroscopy (ICP) was determined (table 1).

\section{Conclusions}

The 7 YSZ nanopowders have been fabricated by a simple Pechini's approach. Industrialization of the YSZ nanopowders was also performed to prepare such oxides on a large scale to test a possible integration of this method into an industrial process. In this case, the structural and microstructural characteristics of materials were strictly preserved. This study underlines the interest of the solgel process, both to control the morphology of oxides and to prepare large amount of powders with the same characteristics (high purity, particle size and distribution).

\section{Acknowledgements}

The authors would like to acknowledge Malek Ashtar University of Technology, Department of Material Engineering, for the financial support.

\section{References}

Badwal S P S and Ciacchi F T 2000 Ionics 61

Casellas D, Feder A, Llanes L and Anglada M 2001 Scr. Mater. 45213
Costa G C C and Muccillo R 2010 J. Alloys Compd. 503474

Farhikhteh S, Maghsoudipour A and Raissi B 2010 J. Alloys Compd. 491402

Gongyi G and Yuli C 1992 J. Am. Ceram. Soc. 751294

Hannink R H J, Kelly P M and Muddle B C 2004 J. Am. Ceram. Soc. 83461

Kingery W D, Pappis J, Doty M E and Hill D C $1959 \mathrm{~J}$. Am. Ceram. Soc. 42393

Kisi E H and Howard C J 1998 Key Eng. Mater. 1531

Laberty-Robert C, Ansart F, Deloget C, Gaudon M and Rousset A 2001 Mater. Res. Bull. 362083

Marcilly Christian, Cqurty Philippe, Delmqn Bernard, Courty P and Delmon B 1970 J. Am. Ceram. Soc. 5356

Mazdiyasni K S, Lynch C T and Ii J S Smith 1967 J. Am. Ceram. Soc. $\mathbf{5 0} 532$

Mazdiyasni K S, Lynch C T and Smith J S 1965 J. Am. Ceram. Soc. 48372

Claussen N, Rühle M and Heuar A 1984 Advances in ceramics, science and technology of zirconia II (The American Ceramic Society: Columbus, $\mathrm{OH}$ )

Oghaz Morteza Hajizadeh, Razavi Reza Shoja Estark, Mohammadreza Loghman and Ghasemi Reza 2012 J. Nano Res. 2165

Roebben G, Basu B, Vleugels J and Van der Biest O 2003 J. Eur. Ceram. Soc. 23481

Rühle M and Evans A G 1989 Prog. Mater. Sci. 3385

Simon C 1991 Ceramics: Today-tomorrow's ceramics (Amsterdam: Elsevier)

Somiya S 1991 Ceramics: Today-tomorrow's ceramics (Amsterdam: Elsevier)

Subbarao E C 1981 Adv. Ceram. 11 